\title{
Effect of Various Surface Treatments on Push-out Strength of Glass Fiber Posts-An In Vitro Study
}

\author{
Navjot Kaur ${ }^{1}$ Manjit Kumar ${ }^{1}$ Amrit Khosla ${ }^{1}$ Ritu Batra ${ }^{1}$ Sumit Katoch ${ }^{1}$ \\ ${ }^{1}$ Department of Prosthodontics, Bhojia Dental College and Hospital, \\ Solan, Himachal Pradesh, India \\ Address for correspondence Navjot Kaur, BDS, MDS, Department \\ of Prosthodontics, Bhojia Dental College and Hospital, Chandigarh \\ - Nalagarh Road, Budh (Baddi), Nalagarh, Solan 173205, Himachal \\ Pradesh, India (e-mail: drnavjottkaur@gmail.com).
}

Dent J Adv Stud 2018;6:28-33

Abstract
Keywords
- glass fiber post
- sand blasting
- hydrofluoric acid
- phosphoric acid
- silane coupling agent
- push-out test
- coronal
- middle and apical
level

Aim The aim of this study was to investigate push-out bond strength of glass fiber posts after various surface treatments and to investigate push-out bond strength at different levels of root (coronal, middle, apical).

Materials and Methods Forty extracted teeth were selected for study (maxillary anteriors and mandibular premolars). Roots were sectioned $16 \mathrm{~mm}$ from apex, endodontically treated and divided into four groups of 10 each based on surface treatment of posts; Group I (Control Group): No treatment of the post, Group II: Post surface were sandblasted and then treatment with silane coupling agent, Group III: Hydrofluoric acid application on the post surface and then treatment with silane coupling agent, Group IV: Post surface treated with 37\% phosphoric acid treatment for 1 minute. Posts after various surface treatments were luted. Roots were then cut into three sections coronal, middle, and apical. The push-out test was done to assess push-out bond strength. The data obtained were statistically analyzed.

Results Hydrofluoric acid and silane coupling agent treatment had little effect on the bond strength of post. Sandblasting and silane coupling agent was proven to be more effective and improved push-out strength of glass fiber posts followed by phosphoric acid group.

Conclusion It was concluded that sandblasting followed by silane coupling agent showed highest bond strength in all parts of the root compared with other surface treatments. Highest push-out strength was found at the coronal level of the root followed by middle and apical level.

\section{Introduction}

Endodontic therapy has equipped a dentist with the ability to retain teeth that used to be indicated for extraction just a few decades ago. A post is given when there is no adequate coronal tooth structure left to hold a core for an artificial crown. The most frequently used posts are custom made posts and prefabricated posts with each having its own advantages and disadvantages. ${ }^{1}$ Glass fiber post is composed of a resin matrix in which glass fibers are embedded and a silane coupling agent holds the fibers in the matrix. Benefit of fiber post is that its closeness of its modulus of elasticity is closer to dentin that creates stress field comparable to natural dentin leading and thus reduces possibility of root fractures. ${ }^{2}$ Another benefit is easy retrievability if endodontic retreatment is mandatory. Bonding effectiveness is pivotal for retention of posts as commonly posts fail due to decementation. ${ }^{3}$

The clinical success of post retention depends on the bonding of post to the luting cement and luting cement with the dentin. Surface treatments are the methods by which general adhesive properties of a material can be enhanced. ${ }^{4}$ To enhance bond strength of glass fiber to root canal, several surface treatments are used: sandblasting followed by the application of a silane, hydrofluoric acid gel and silane
DOI https://doi.org/

$10.1055 / \mathrm{s}-0038-1673571$

ISSN 2321-1482.
C2018 by Bhojia Dental College and Hospital affiliated to Himachal Pradesh University
License terms

(ㄷ) (1) $\ominus \circledast$ 
coupling agent, application of silane coupling agent only, and treatment with phosphoric acid. Therefore, the purpose of this article is to investigate effect of various surface treatments on push-out strength of glass fiber posts.

\section{Materials and Methods}

\section{Sample Collection and Their Storage}

Forty extracted single rooted teeth with oval canal were collected (Maxillary anteriors and mandibular premolars). Roots with canal diameter of more than $2 \mathrm{~mm}$ were not included in study. The teeth were cleaned and stored in $0.9 \%$ saline solution. Roots of teeth were cut horizontally at $16 \mathrm{~mm}$ length, perpendicular to long axis of teeth with the help of diamond disc under copious water irrigation from their anatomical apex. The specimens were kept at normal room temperature in normal saline.

\section{Endodontic Treatment of the Teeth}

Patency of canals was checked using a no. $10 \mathrm{~K}$ file. A no. 15 $\mathrm{K}$ file was used to determine working length and calculated by radiograph. Root canals were them prepared using Protaper Hand instruments starting from SX to F3. In between instrumentation irrigation was accomplished using $5 \% \mathrm{NaO}-$ $\mathrm{Cl}$ and absorbent paper points were used to dry the canals. Obturation was done by lateral condensation method using gutta-percha and AH plus sealer. Samples were kept for resin sealer setting at $37^{\circ} \mathrm{C}$.

\section{Post Space Preparation}

Gutta-percha was removed from root canals in all 40 samples with peeso-reamers (Mani, Prime Dental Products, India) one to three leaving $5 \mathrm{~mm}$ apical gutta-percha. Post space was prepared by using specific drill (3M) for the prefabricated post. Drill was marked at $10 \mathrm{~mm}$ from tip with marker and then post space prepared. Finally post spaces were irrigated with distilled water and canals were dried.

The samples were then divided into four groups (10 samples each) according to the type of surface treatment. 3M Glass fiber post of size 2 was used in this study. Post were tried in their corresponding post spaces inside the root canals of extracted teeth. Post spaces were dried for all teeth to receive the fiber post.

\section{Post Surface Treatments}

- Group I: No surface treatment of the glass fiber post was done.

- Group II: Posts were sandblasted in sandblasting machine using $50 \mu \mathrm{m}$ aluminum oxide particles for 20 seconds at a distance of $10 \mathrm{~mm}$ and then posts were treated with silane coupling agent for 1 minute and air dried for 1 minute.

- Group III: Etching using hydrofluoric acid then silane coating (E + SC). The posts were etched with 9.5\% hydrofluoric acid for 90 seconds. After 2 minutes rinsing with running water, samples were air dried. The posts were then painted using silane coupling agent and allowed to air dry for 5 minutes.
- Group IV: $37 \%$ phosphoric acid treatment was done on surface of posts for 1 minute and then rinsed with distilled water and air dried (- Fig. 1).

All surface treated posts were luted with dual cure resin cement and then light polymerized. In all samples, post coming out and apical $5 \mathrm{~mm}$ was cut off using diamond disc (under water irrigation).

\section{Sectioning of Tooth}

Each root was sectioned to obtain $2 \mathrm{~mm}$ thick coronal, middle, and apical section from each sample leaving $1 \mathrm{~mm}$ of tooth intact in between ( - Fig. 2). A total of 120 sections were obtained with 30 sections in each group.

\section{Stainless Steel Die}

A stainless steel die was manufactured by Computer Numerical Control (CNC) milling machine. This die consisted of three plates: upper, middle, and lower (-Fig. 3). All three parts could be connected while testing the samples. Dimensions of each plate were $50 \times 70 \times 5 \mathrm{~mm}$ in dimension. Upper plate had hole in center approximately $1 \mathrm{~cm}$ in diameter. This hole was made for the entry of testing tool. The middle plate basically was for making samples. Middle part had a rectangular

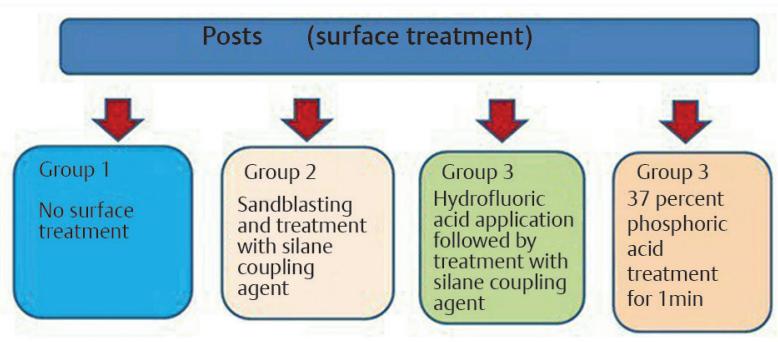

Fig. 1 Post surface treatments.

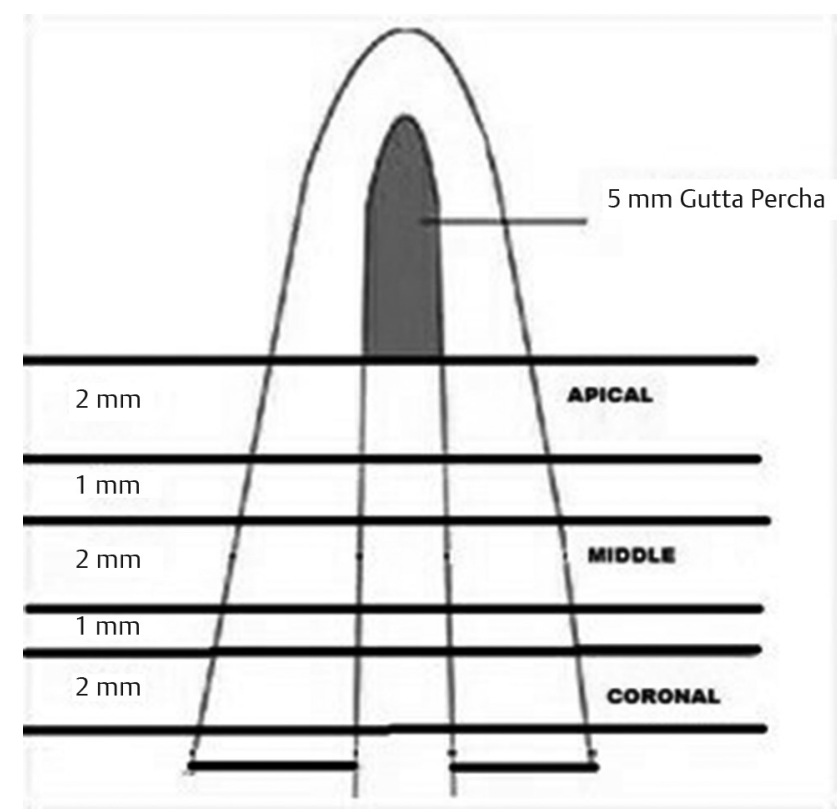

Fig. 2 Sectioning of tooth. 
area in center $30 \times 10 \mathrm{~mm}$ in dimensions with height of $2 \mathrm{~mm}$ and hole at its base of $2.5 \mathrm{~mm}$ in diameter. Samples were fabricated in middle part. Lower plate was for connecting upper plates and stabilizing them while testing.

\section{Formation of Acrylic Blocks}

The tooth sections with glass fiber posts were centered over the hole in the middle part of die after application of vaseline, then self-cure acrylic resin was filled onto this middle part (-Fig. 4). Each tooth section was positioned with coronal part downwards and apical part on top. In such a manner all 120 tooth sections were embedded in acrylic resin $10 \times 30 \mathrm{~mm}$ in dimension.

\section{Testing of the Samples}

Testing was done by positioning prepared acrylic blocks in the middle part of die that oriented the specimen at an angle of 90 degrees to the load application tip of the attachment tool. The die with acrylic blocks was fitted in the universal testing machine ( $\mathbf{- F i g . 5}$ ).

Load was applied progressively at a speed of $1 \mathrm{~mm} / 60$ seconds on the apical aspect in center of post using attachment tool fitted in Universal Testing Machine until posts extruded out.

Load required for extrusion which was recorded in Newton was converted to bond strength in MPa by dividing load in Newton by area of post as calculated by following formula:

$A=\pi(a+b)\left[\left(h^{2}+(a b)^{2}\right] 0.5\right.$, where $\pi$ is the constant 3.14, $a$ is post radius at corornal region, $b$ is post radius at apical region, and $h$ is the thickness of the slice in millimeters. Thus Push-out strength was calculated for each sample and all

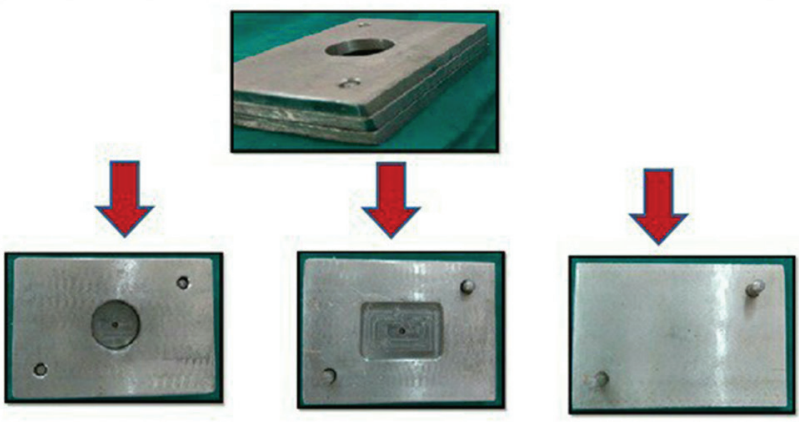

Fig. 3 Stainless steel die.

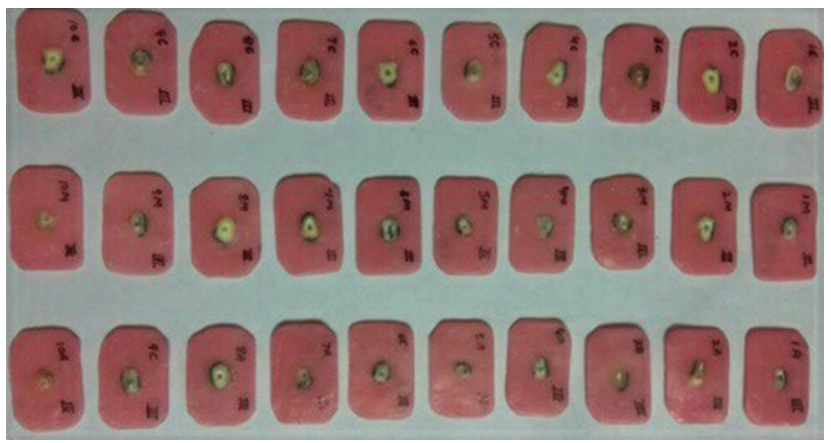

Fig. 4 Formation of acrylic blocks. values obtained were tabulated and subjected to statistical analysis.

\section{Results}

Following observations were made from the statistical analysis done.

- Mean and standard deviation (SD) for different surface treatments at coronal, middle, and apical levels were calculated (-Table 1). Comparison of mean for different surface treatments at coronal, middle, and apical levels was done (-Table 2). Analysis of variance (one-way ANOVA) was applied to determine the comparison between different groups. The difference between means at coronal level among groups was highly significant. The difference between means at middle level among groups was highly significant. The difference between means at apical level among groups was highly significant.

- Post hoc Tukey's test (Bonferroni) was done for multiple comparisons (-Table 3). Mean difference at coronal, middle, apical level between no treatment group and HF (hydrofluoric acid) + SCA (Silane coupling agent) was not significant. Mean difference at coronal, middle, apical level between no treatment group and SB (sand blasting) + SCA and $\mathrm{H}_{3} \mathrm{PO}_{4}$ was significant.

- In case of no treatment group, difference between means for coronal and middle was significant, coronal and apical was highly significant, and middle and apical was significant. In case of SB + SCA group, difference between means for coronal and middle was significant, coronal and apical was highly significant, and middle and apical was not significant. In case of HF + SCA group, difference between means for coronal and middle was significant, coronal and apical was highly significant, and middle and apical was not significant. In case of $\mathrm{H}_{3} \mathrm{PO}_{4}$ group, difference between means for coronal and middle was not significant and coronal and apical was highly significant.

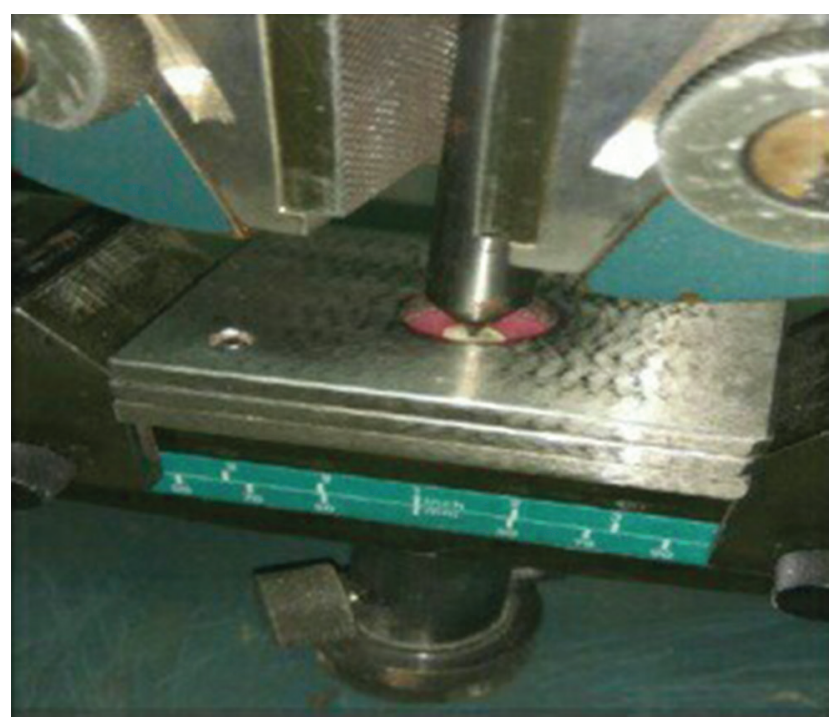

Fig. 5 Testing of the samples. 
Table 1 Mean and standard deviation for different surface treatments at coronal, middle, and apical levels

\begin{tabular}{|c|c|c|c|c|c|c|c|c|c|}
\hline & & \multirow[t]{2}{*}{$N$} & \multirow[t]{2}{*}{ Mean } & \multirow[t]{2}{*}{ SD } & \multirow[t]{2}{*}{ SE } & \multicolumn{2}{|c|}{$\begin{array}{l}95 \% \text { confidence interval } \\
\text { for mean }\end{array}$} & \multirow[t]{2}{*}{ Minimum } & \multirow[t]{2}{*}{ Maximum } \\
\hline & & & & & & Lower bound & Upper bound & & \\
\hline \multirow[t]{4}{*}{ Coronal } & No treatment & 10 & 11.1130 & 1.25495 & 0.39685 & 10.2153 & 12.0107 & 9.41 & 12.81 \\
\hline & $\mathrm{SB}+\mathrm{SCA}$ & 10 & 17.6390 & 1.17814 & 0.37256 & 16.7962 & 18.4818 & 16.21 & 19.83 \\
\hline & $\mathrm{HF}+\mathrm{SCA}$ & 10 & 12.2910 & 1.08757 & 0.34392 & 11.5130 & 13.0690 & 10.06 & 13.95 \\
\hline & $\mathrm{H}_{3} \mathrm{PO}_{4}$ & 10 & 14.3980 & 1.11437 & 0.35239 & 13.6008 & 15.1952 & 12.88 & 16.84 \\
\hline \multirow[t]{4}{*}{ Middle } & No treatment & 10 & 9.5410 & 0.87384 & 0.27633 & 8.9159 & 10.1661 & 8.34 & 10.94 \\
\hline & $\mathrm{SB}+\mathrm{SCA}$ & 10 & 15.2850 & 1.31247 & 0.41504 & 14.3461 & 16.2239 & 13.42 & 16.92 \\
\hline & $\mathrm{HF}+\mathrm{SCA}$ & 10 & 10.1020 & 1.03029 & 0.32581 & 9.3650 & 10.8390 & 8.55 & 11.78 \\
\hline & $\mathrm{H}_{3} \mathrm{PO}_{4}$ & 10 & 13.2570 & 0.76617 & 0.24229 & 12.7089 & 13.8051 & 11.93 & 14.55 \\
\hline \multirow[t]{4}{*}{ Apical } & No treatment & 10 & 8.0740 & 0.91014 & 0.28781 & 7.4229 & 8.7251 & 6.48 & 9.32 \\
\hline & $\mathrm{SB}+\mathrm{SCA}$ & 10 & 13.9790 & 1.60575 & 0.50778 & 12.8303 & 15.1277 & 11.06 & 16.68 \\
\hline & $\mathrm{HF}+\mathrm{SCA}$ & 10 & 9.0830 & 0.84688 & 0.26781 & 8.4772 & 9.6888 & 7.83 & 10.26 \\
\hline & $\mathrm{H}_{3} \mathrm{PO}_{4}$ & 10 & 10.9780 & 1.38823 & 0.43900 & 9.9849 & 11.9711 & 8.58 & 13.06 \\
\hline
\end{tabular}

Abbreviations: HF, hydrofluoric acid; N, push-out bond strength in Mpa; SB, sand blasting; SCA, silane coupling agent; SD, standard deviation; $\mathrm{SE}$, standard error.

Table 2 Comparison of mean for different surface treatments at coronal, middle, and apical levels (one-way ANOVA)

\begin{tabular}{|l|l|l|l|l|l|l|}
\hline \multirow{5}{*}{ Coronal } & & Sum of squares & df & $\begin{array}{l}\text { Mean } \\
\text { square }\end{array}$ & F & $p$-Value \\
& Between groups & 245.781 & 3 & 81.927 & 60.827 & $<0.001^{\text {a }}$ \\
\cline { 2 - 8 } & Within groups & 48.488 & 36 & 1.347 & & \\
\cline { 2 - 8 } & Total & 294.268 & 39 & & & \\
\hline \multirow{4}{*}{ Middle } & Between groups & 220.118 & 3 & 73.373 & 70.982 & $<0.001^{\text {a }}$ \\
\cline { 2 - 8 } & Within groups & 37.212 & 36 & 1.034 & & \\
\cline { 2 - 8 } & Total & 257.330 & 39 & & & \\
\hline \multirow{3}{*}{ Apical } & Between groups & 202.220 & 3 & 67.407 & 44.558 & $<0.001^{\text {a }}$ \\
\cline { 2 - 8 } & Within groups & 54.461 & 36 & 1.513 & & \\
\cline { 2 - 7 } & Total & 256.681 & 39 & & & \\
\hline
\end{tabular}

Abbreviations: ANOVA, analysis of variance; df, degrees of freedom; F, ratio of Between-Groups to Within-Groups Variances.

${ }^{a} p<0.001$ is highly significant.

- Graphical representation of the mean, maximum, and minimum push-out bond strength of coronal region, middle, and apical level for different surface treatments are shown in -Figs. 6-8.

\section{Discussion}

The use of glass fiber posts was selected as a material of choice for present study. Prefabricated fiber posts are considered to be less damaging to remaining tooth structure as its modulus of elasticity is closer to dentin. ${ }^{5}$

Thin-slice push-out test is considered to be superior over conventional and modified microtensile bond strength testing methods as it allows testing at different levels of root and many specimens can be acquired from one root. ${ }^{6}$
Benefits of present study also showed higher bond strength values in the coronal compared with middle and then apical root regions in all surface treatment groups which is similar to previous studies as suggested by Van Meerbeek et al, ${ }^{7}$ Ngoh et al, ${ }^{8}$ and Bouillaguet et al. ${ }^{9}$

Higher bond strength at coronal level and less strength at apical level may be due to inability of curing light to completely reach apical level compared with coronal level as explained earlier by Ferrari et al. ${ }^{10}$ Problem with moisture control in apical region may also affect proper bonding of cement. ${ }^{11}$

In the present study, the highest bond strength was obtained in sandblasting and silane coupling agent surface treatment which resulted in improvement in the overall bond strength as compared with the control 
Table 3 Post hoc Tukey's test (Bonferroni)

\begin{tabular}{|c|c|c|c|c|c|c|c|}
\hline \multirow[t]{2}{*}{ Group } & \multirow[t]{2}{*}{ (I) $\mathrm{C} / \mathrm{M} / \mathrm{A}$} & \multirow[t]{2}{*}{ (J) $\mathrm{C} / \mathrm{M} / \mathrm{A}$} & \multirow{2}{*}{$\begin{array}{l}\text { Mean difference } \\
\text { (I J) }\end{array}$} & \multirow[t]{2}{*}{ SE } & \multirow[t]{2}{*}{ Sig. } & \multicolumn{2}{|c|}{ 95\% confidence interval } \\
\hline & & & & & & Lower bound & Upper bound \\
\hline \multirow[t]{6}{*}{ No treatment } & \multirow[t]{2}{*}{ Coronal } & Middle & 1.57200 & 0.45948 & 0.006 & 0.3992 & 2.7448 \\
\hline & & Apical & 3.03900 & 0.45948 & $<0.001$ & 1.8662 & 4.2118 \\
\hline & \multirow[t]{2}{*}{ Middle } & Coronal & -1.57200 & 0.45948 & 0.006 & -2.7448 & -0.3992 \\
\hline & & Apical & 1.46700 & 0.45948 & 0.011 & 0.2942 & 2.6398 \\
\hline & \multirow[t]{2}{*}{ Apical } & Coronal & -3.03900 & 0.45948 & $<0.001$ & -4.2118 & -1.8662 \\
\hline & & Middle & -1.46700 & 0.45948 & 0.011 & -2.6398 & -0.2942 \\
\hline \multirow[t]{6}{*}{$\mathrm{SB}+\mathrm{SCA}$} & \multirow[t]{2}{*}{ Coronal } & Middle & 2.35400 & 0.61585 & 0.002 & 0.7821 & 3.9259 \\
\hline & & Apical & 3.66000 & 0.61585 & $<0.001$ & 2.0881 & 5.2319 \\
\hline & \multirow[t]{2}{*}{ Middle } & Coronal & -2.35400 & 0.61585 & 0.002 & -3.9259 & -0.7821 \\
\hline & & Apical & 1.30600 & 0.61585 & 0.130 & -0.2659 & 2.8779 \\
\hline & \multirow[t]{2}{*}{ Apical } & Coronal & -3.66000 & 0.61585 & $<0.001$ & -5.2319 & -2.0881 \\
\hline & & Middle & -1.30600 & 0.61585 & 0.130 & -2.8779 & 0.2659 \\
\hline \multirow[t]{6}{*}{$\mathrm{HF}+\mathrm{SCA}$} & \multirow[t]{2}{*}{ Coronal } & Middle & 2.18900 & 0.44434 & $<0.001$ & 1.0549 & 3.3231 \\
\hline & & Apical & 3.20800 & 0.44434 & $<0.001$ & 2.0739 & 4.3421 \\
\hline & \multirow[t]{2}{*}{ Middle } & Coronal & -2.18900 & 0.44434 & $<0.001$ & -3.3231 & -1.0549 \\
\hline & & Apical & 1.01900 & 0.44434 & 0.090 & -0.1151 & 2.1531 \\
\hline & \multirow[t]{2}{*}{ Apical } & Coronal & -3.20800 & 0.44434 & $<0.001$ & -4.3421 & -2.0739 \\
\hline & & Middle & -1.01900 & 0.44434 & 0.090 & -2.1531 & 0.1151 \\
\hline \multirow[t]{6}{*}{$\mathrm{H}_{3} \mathrm{PO}_{4}$} & \multirow[t]{2}{*}{ Coronal } & Middle & 1.14100 & 0.50040 & 0.092 & -0.1363 & 2.4183 \\
\hline & & Apical & 3.42000 & 0.50040 & $<0.001$ & 2.1427 & 4.6973 \\
\hline & \multirow[t]{2}{*}{ Middle } & Coronal & -1.14100 & 0.50040 & 0.092 & -2.4183 & 0.1363 \\
\hline & & Apical & 2.27900 & 0.50040 & $<0.001$ & 1.0017 & 3.5563 \\
\hline & \multirow[t]{2}{*}{ Apical } & Coronal & -3.42000 & 0.50040 & $<0.001$ & -4.6973 & -2.1427 \\
\hline & & Middle & -2.27900 & 0.50040 & $<0.001$ & -3.5563 & -1.0017 \\
\hline
\end{tabular}

Abbreviations: A, apical; C, coronal; HF, hydrofluoric acid; H3PO4, phosphoric acid; M, middle; SB, sandblasting; SCA, silane coupling agent; SE, standard error.

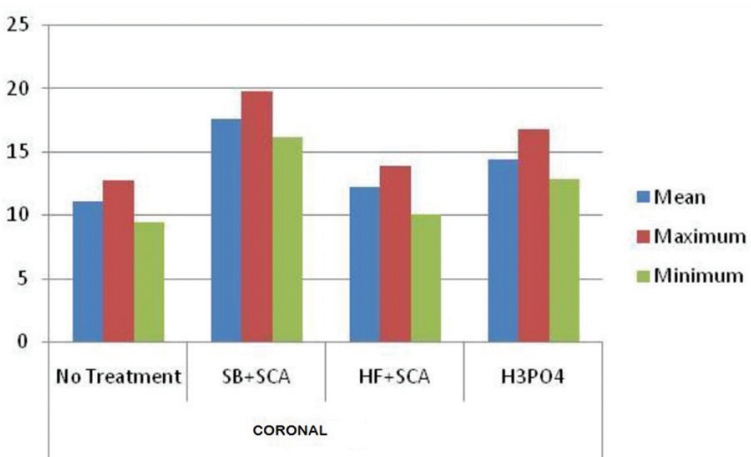

Fig. 6 Depicting the mean, maximum, and minimum push-out bond strength of coronal region for different surface treatments.

group. Sandblasting leads to roughening of post surface by removing the resin matrix between the silicon fibers that increases retention in addition to the chemical reaction of silanes and conversion of the mineral surface into a less polar surface compatible with organic bonding agent. These conclusions were similar to those attained by Perdigao et al ${ }^{12}$ and Balbosh et al. ${ }^{13}$

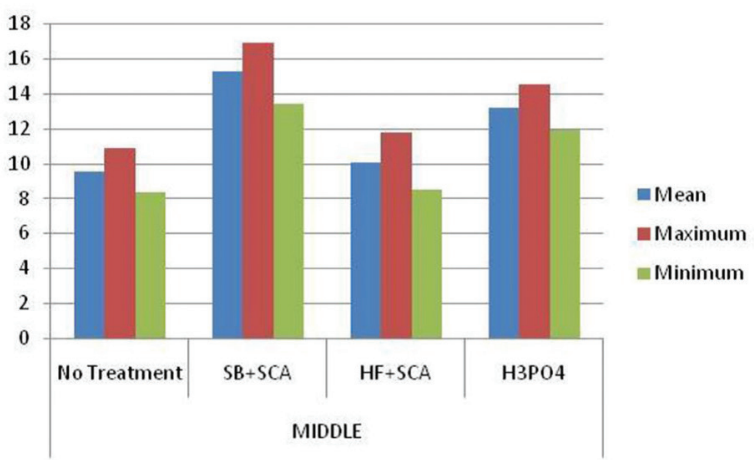

Fig. 7 Depicting the mean, maximum, and minimum push-out bond strength of middle region for different surface treatments.

In the present study the bond strength that was obtained in phosphoric acid treatment was higher than that of no treatment group and these findings were similar to those attained by Majeti et al. ${ }^{14}$

No statistically significant results were seen with hydrofluoric acid and silane coupling agent treated posts compared with no treatment posts group. 


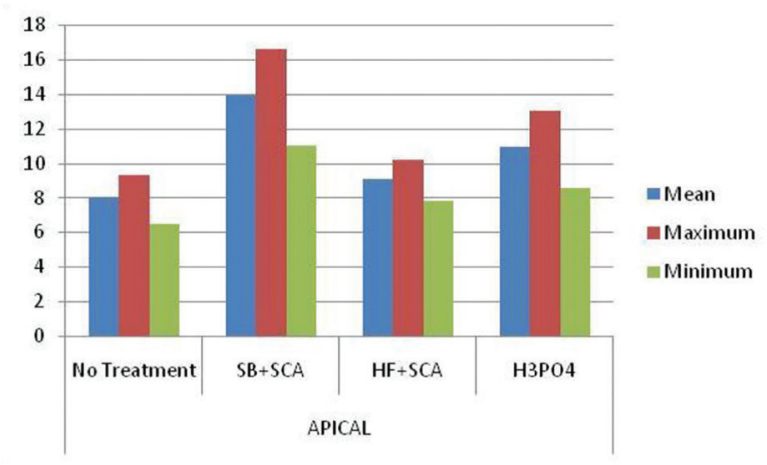

Fig. 8 Depicting the mean, maximum, and minimum push-out bond strength of apical region for different surface treatments.

\section{Summary and Conclusion}

Within the limitations of the present study it was found that:

- Hydrofluoric acid and silane coupling agent treatment has little effect on the bond strength of fiber post.

- Sandblasting and silane coupling agent was proven to be better and improved push-out strength of glass fiber posts followed by phosphoric acid group.

- Highest push-out strength was achieved at the coronal level followed by middle and apical level.

\section{Funding}

None.

\section{Conflict of Interest}

None.

\section{References}

1 Abou-Rass M. Post and core restoration of endodontically treated teeth. Curr Opin Dent 1992(2):99-107
2 Mohsen CA. Evaluation of push-out bond strength of surface treatments of two esthetic posts. Indian J Dent Res 2012;23(5):596-602

3 Gencoglu N, Sezgin P, Gundogar M, Sivet C. The effect of surface treatments on the bond strength of fiberpost to root canal dentin. Marmara Dent J 2013;1:35-38

4 Narene AV, Shankar P, Indira R. Effect of surface treatments on push out strength of three glass fiber posts: an in vitro study. Indian J Multidisp Dent 2011;5(5):255-259

5 Al-Wahadni AM, Hamdan S, Al-Omiri M, Hammad MM, Hatamleh MM. Fracture resistance of teeth restored with different post systems: in vitro study. Oral Surg Oral Med Oral Pathol Oral Radiol Endod 2008;106(2):e77-e83

6 Goracci C, Tavares AU, Fabianelli A, et al. The adhesion between fiber posts and root canal walls: comparison between microtensile and push-out bond strength measurements. Eur J Oral Sci 2004;112(4):353-361

7 Van Meerbeek B, De Munck J, Yoshida Y, et al. Buonocore memorial lecture. Adhesion to enamel and dentin: current status and future challenges. Oper Dent 2003;28(3):215-235

8 Ngoh EC, Pashley DH, Loushine RJ, Weller RN, Kimbrough WF. Effects of eugenol on resin bond strengths to root canal dentin. J Endod 2001;27(6):411-414

9 Bouillaguet S, Troesch S, Wataha JC, Krejci I, Meyer JM, Pashley DH. Microtensile bond strength between adhesive cements and root canal dentin. Dent Mater 2003;19(3):199-205

10 Ferrari M, Mannocci F, Vichi A, Cagidiaco MC, Mjör IA. Bonding to root canal: structural characteristics of the substrate. Am J Dent 2000;13(5):255-260

11 Bitter K, Noetzel J, Neumann K, Kielbassa AM. Effect of silanization on bond strengths of fiber posts to various resin cements. Quintessence Int 2007;38(2):121-128

12 Perdigão J, Geraldeli S, Lee IK. Push-out bond strengths of tooth-colored posts bonded with different adhesive systems. Am J Dent 2004;17(6):422-426

13 Balbosh A, Kern M. Effect of surface treatment on retention of glass-fiber endodontic posts. J Prosthet Dent 2006;95(3):218-223

14 Majeti C, Veeramachaneni C, Morisetty PK, et al. A simplified etching technique to improve the adhesion of fiber post. J Adv Prosthodont 2014;6:295-301 